\title{
LA DISCIPLINA HISTORIA DE LAS MATEMÁTICAS EN LA UNIVERSIDAD FEDERAL DEL TRIÁNGULO MINERO: UN BREVE INFORME
}

\author{
Mônica de Cássia Siqueira Martines \\ monicasiqueiramartines@gmail.com \\ Universidade Federal do Triângulo Mineiro
}

Recibido: 22/12/2019 Aceptado: 22/02/2020

\begin{abstract}
Resumen
Este artículo describe los resultados de un experimento que involucró la enseñanza y la investigación en la disciplina de Historia de las Matemáticas, impartido por el autor en la Universidad Federal de Triângulo Mineiro (UFTM) desde el comienzo de la oferta del Grado en Matemáticas en esa institución de educación superior. En este sentido, presentamos el formato de las clases y evaluaciones que se realizan para el tema del estudio que originó este artículo. La investigación desarrollada fue del tipo cualitativo, en particular un estudio de caso, ya que la experiencia descrita y explicada se centra en la preocupación por los aspectos de la realidad del aula de una sola situación específica. Los resultados muestran la necesidad de reflexión constante, diálogo y posibles cambios en la didáctica en el aula, ya que los estudiantes, cada día, son diferentes en un mundo globalizado e informatizado. También revelan la necesidad de invitar a los estudiantes a asumir el papel de protagonistas, de modo que las formas de evaluación para cada clase puedan modificarse.
\end{abstract}

Palabras clave: Historia de las matemáticas; Evaluación; Formación inicial de profesores de matemáticas.

\section{THE DISCIPLINE HISTORY OF MATHEMATICS AT THE FEDERAL UNIVERSITY OF THE MINING TRIANGLE: A BRIEF REPORT}

\begin{abstract}
This article describes the results of an experiment that involved teaching and research in the History of Mathematics discipline, taught by the author at the Federal University of Triângulo Mineiro (UFTM) since the beginning of the offer of the Degree in Mathematics at that institution of higher education. In this sense, we present the format of the classes and assessments that are carried out for the subject of the study that originated this article. The research developed was of the qualitative type, particularly a case study, since the experience described and explained is centered on the concern with aspects of the classroom reality of a single specific situation. The results show the need for constant reflection, dialogue and possible change in the didactics in the classroom, since the students, each day, are different in a globalized and computerized world. They also reveal the need to invite students to assume the role of protagonists, so that the forms of assessment for each class can be modified.
\end{abstract}

Keywords: History of Mathematics; Evaluation; Initial training of mathematics teachers. 


\title{
A DISCIPLINA HISTÓRIA DA MATEMÁTICA NA UNIVERSIDADE FEDERAL DO TRIÂNGULO MINEIRO: UM BREVE RELATO
}

\begin{abstract}
Resumo
Este artigo descreve os resultados de uma experiência que envolveu ensino e pesquisa na disciplina História da Matemática, ministrada pela autora na Universidade Federal do Triângulo Mineiro (UFTM) desde o início da oferta do curso de Licenciatura em Matemática na referida instituição de ensino superior. Neste sentido apresentamos o formato das aulas e avaliações que são realizadas para a disciplina foco do estudo que originou este artigo. A pesquisa desenvolvida foi do tipo qualitativa, particularmente um estudo de caso, uma vez que a experiência descrita e explicada está centrada na preocupação com os aspectos da realidade da sala de aula de uma única situação especifica. Os resultados mostram a necessidade de constante reflexão, diálogo e possível alteração na didática em sala de aula, visto que os(as) alunos(as), a cada dia, se mostram diferentes perante um mundo globalizado e informatizado. Revelam, também, a necessidade de convidar os(as) alunos(as) a assumirem o papel de protagonistas, fazendo com que as formas de avaliação de cada turma possam ser modificadas. Palavras-chave: História da Matemática; Avaliação; Formação inicial de professores de matemática.
\end{abstract}

\section{Introdução}

Este trabalho tem por objetivo apresentar um breve relato sobre a disciplina de História da Matemática ministrada pela autora na Universidade Federal do Triângulo Mineiro (UFTM) e sobre a forma como essa disciplina vem sendo ministrada e avaliada.

A disciplina História da Matemática faz parte da grade curricular do curso de Licenciatura em Matemática da UFTM desde sua implantação em 2009. A disciplina foi "concebida" com 60h/a de aula teórica presencial e mais $15 \mathrm{~h} / \mathrm{a}$ de atividade prática como componente curricular (APC) que poderia ser realizada a distância com acompanhamento via plataforma Moodle.

Para que a disciplina fosse estruturada, foi observada a legislação então em vigor PARECER CNE/CES 1.302/2001 o qual orientou para melhorias e transformações na formação do Bacharel e do Licenciado em Matemática. Para ambos os cursos, nesse parecer, foi definido um rol de disciplinas a serem oferecidas. Para a licenciatura, em específico, foram descritas as disciplinas: Cálculo Diferencial e Integral, Álgebra Linear, Fundamentos de Análise, Fundamentos de Álgebra, Fundamentos de Geometria, Geometria Analítica. Também ficou estabelecido que: 
A parte comum deve ainda incluir: a) conteúdos matemáticos presentes na educação básica nas áreas de Álgebra, Geometria e Análise; b) conteúdos de áreas afins à Matemática, que são fontes originadoras de problemas e campos de aplicação de suas teorias; c) conteúdos da Ciência da Educação, da História e Filosofia das Ciências e da Matemática. (BARRETO, OLIVEIRA \& BEZERRA, 2002, p. 6, grifo da autora)

Dessa maneira, a disciplina História da Matemática foi incluída na grade curricular como obrigatória no curso de Licenciatura em Matemática da UFTM.

Os objetivos da disciplina foram definidos seguindo as orientações de Nobre (2012, p.510), os quais foram incorporados ao plano de ensino:

OBJETIVOS GERAIS: Proporcionar ao aluno condições de: Desenvolver sua capacidade de formulação e interpretação de situações matemáticas; Desenvolver seu espírito crítico e criativo; Perceber e compreender o relacionamento entre as diversas áreas da Matemática apresentadas ao longo do Curso. Organizar, comparar e aplicar os conhecimentos adquiridos. OBJETIVOS ESPECÍFICOS: Contrapor-se à perversão formalista de reinterpretar logicamente, segundo a ordem das razões, a gênese real dos conceitos, segundo a ordem das ideias; Mostrar que a Matemática formalizada é precedida por uma Matemática informal e quase empírica (sem caráter científico, baseada na experiência), que não se desenvolve como uma sequência inexorável de teoremas acumulados estabelecidos além de toda a dúvida, mas por uma dialética própria, pelo jogo das conjecturas através da especulação, da crítica e da dinâmica dos interesses práticos e teóricos. Mostrar que existe uma ligação muito forte entre o desenvolvimento social e o desenvolvimento da Matemática. (SIQUEIRA MARTINES, 2012)

Assim como os objetivos, a ementa proposta para a disciplina, também foi baseada em Nobre (2012, p.520), para ficar em consonância aos objetivos apresentados, é constituída pelo estudo da Matemática na Antiguidade, Matemática no Mundo Grego, Matemática nos países Árabes, na Índia e na China e Matemática na Europa.

A primeira oferta da disciplina ocorreu no segundo semestre de 2012. No referido ano, e nos anos subsequentes, foi proposto aos(às) alunos(as), aulas expositivas e dialogadas. As aulas dialogadas foram propostas para que houvesse maior interação entre professora e alunos(as) e, assim, dialogando, chegamos às atividades avaliativas das aulas teóricas e das aulas de APC da seguinte maneira:

$$
\checkmark \quad \text { duas avaliações individuais, }
$$




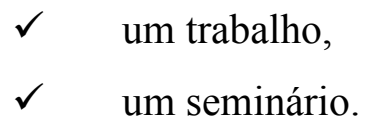

Através destas atividades é esperado que o discente e, futuro professor, possa refletir sobre a Matemática que irá ensinar, respondendo a alguns dos "por quês" da Matemática.

\section{Desenvolvimento}

Visando atingir os objetivos gerais da disciplina descritos anteriormente, semestralmente, são propostas duas avaliações individuais. Ambas as avaliações, são constituídas por cinco questões do tipo dissertativas, que se baseiam na resolução de exercícios, tais como o exercício 36 proposto por Nobre (2012, p. 519) "Discorra sobre os temas: Binômio de Newton, Triângulo de Pascal e Relações de Stifel. Faça uma análise histórica deste tema comparando a época à qual cada um viveu."

Essas avaliações são solicitadas pensando na formação do(a) aluno(a), uma vez que durante as aulas expositivas e dialogadas, questões assim são apresentadas, e os(as) alunos(as) são conduzidos a resolverem as mesmas usando as técnicas de cada povo apresentado e discutido, vivenciando o processo criativo da matemática, mostrando que as fórmulas não “caem do céu”. Quando penso em avaliação para a formação do(a) aluno(a) penso, e vivencio em minha prática, que este ainda não está preparado para se responsabilizar pela própria aprendizagem, ainda é necessário que façamos avaliações para exigirmos que estudem, que reflitam, que problematizem, que exponham a opinião baseada na ciência. Como evidenciado por Gaspar (2003, p.39),

Em um curso de formação de professores deve-se criar um ambiente que coloque em prática métodos e técnicas pedagógicas que levem os alunos a vivenciarem o processo criativo inerente à matemática levando em conta o nível de escolaridade do aluno. Que esses futuros professores tenham uma consciência crítica e renovadora da relação pedagógica tradicional e que seja problematizada e questionada a transmissão dogmática dos saberes matemáticos. (GASPAR, 2003, p.39)

Para alcançar um dos objetivos específicos da disciplina "Contrapor-se à perversão formalista de reinterpretar logicamente, segundo a ordem das razões, a gênese real dos conceitos, segundo a ordem das ideias", foi proposta uma avaliação para as aulas de atividades 
práticas curriculares (APC). Sugeri a apresentação de um trabalho com atividades que correlacionassem a disciplina História da Matemática e a Educação Básica.

Ao longo de cada semestre letivo são sugeridas leituras e, posteriores discussões em sala de aula virtual, via Moodle, de textos sobre o uso da História da Matemática como recurso pedagógico.

Segundo Mendes (2008, p.41),

Para efetivarmos um ensino-aprendizagem significativo em matemática, é necessário utilizarmos as atividades históricas, buscarmos no material histórico existente todas as informações úteis à condução da nossa ação docente e somente a partir daí orientar os estudantes à realização de atividades. (MENDES, 2008, p.41)

Nas aulas de APC, esse caráter é reafirmado aos discentes, ou seja, é indicado aos mesmos que busquem os materiais históricos existentes em diversos locais: biblioteca física, biblioteca digital (Biblioteca Nacional do Rio de Janeiro, Gállica, etc.), sites como Mac Tutor ou da Revista Brasileira de História da Matemática, entre outros. Ao mesmo tempo em que fazem a procura por esse tipo de material, se torna necessário discutir as fontes que podem ser usadas para realizar as atividades.

De acordo com Nobre (2004, p. 541) “o papel do historiador é sempre estar atento à origem das informações que recebe e à diversidade dos caminhos que levaram à concepção do fato histórico consumado." Os discentes são alertados sobre o trabalho do historiador que interpreta os documentos que dispõe, nesse sentido, torna-se interessante buscarem por mais de um autor sobre o mesmo assunto, para que possam analisar e obterem maior propriedade sobre o assunto a ser tratado.

Ao longo dos semestres letivos de ofertas do curso, essa atividade foi sendo monitorada e alterada. Hoje, em cada semestre é indicado um ano (série) para se trabalhar a História da Matemática como recurso pedagógico. O conteúdo pode ser escolhido pelo licenciando, desde que esteja em acordo ao ano solicitado e comprovado pelo documento oficial do estado de Minas Gerais, hoje é o Currículo Referência de Minas Gerais, documento aprovado em 2019, já em acordo com as Base Nacional Comum Curricular (BNCC), até o segundo semestre de 2018, usávamos o Conteúdo Básico Comum (CBC) - Matemática. Como é uma atividade da disciplina a mesma é avaliada pela apresentação e pelo trabalho escrito. 
$\mathrm{Na}$ apresentação do trabalho, o licenciando deve conduzir a atividade escolhida como se estivesse trabalhando com os(as) alunos(as) da educação básica. Todas as atividades programadas devem ser aplicadas aos demais colegas de turma. Para o trabalho escrito, os discentes são incentivados a seguir as normas da ABNT, escrevendo um plano de aula completo, inclusive com atividades usando a História da Matemática como recurso pedagógico no item desenvolvimento do plano de ensino.

As atividades usando a História da matemática como recurso pedagógico devem ser conduzidas de modo que o(a) aluno(a) resgate o processo histórico da construção dos tópicos matemáticos escolhidos a serem abordados em sala de aula (MENDES, 2008, p.42).

Aos graduandos é requerido refletir sobre como cada tema escolhido foi sendo moldado ao longo dos séculos, percebendo a Matemática como "uma ciência desenvolvida pela humanidade, passível de erros e construída a partir de muitas tentativas em solucionar problemas cotidianos.” (LOPES \& FERREIRA, 2013, p. 78).

Para que os(as) alunos(as) consigam elaborar o material usando a História da Matemática como recurso pedagógico, esse trabalho é a última tarefa a ser cobrada no semestre, na última semana de aula da disciplina, após as atividades na plataforma Moodle terem sido completadas. Nessa plataforma são indicados textos, dissertações de mestrado e de doutorado em que a Tendência Metodológica História da Matemática é usada em sala de aula. Também nessa plataforma são criadas ferramentas para diálogos sobre o assunto. Todas as atividades disponibilizadas na plataforma devem ser realizadas ao longo do semestre letivo.

Para alcançar outro objetivo "Mostrar que existe uma ligação muito forte entre o desenvolvimento social e o desenvolvimento da Matemática.”, a partir do segundo semestre de 2013 indiquei aos(às) alunos(as) apresentar um seminário. Neste seminário os(as) alunos(as) deveriam relatar:

i. um resultado matemático proposto por um(a) cientista do século determinado pela professora;

ii. a época em que esse(a) cientista viveu contextualizando o assunto tratado;

iii. um breve estudo sobre a vida deste(a) cientista;

iv. um estudo sobre o resultado matemático estudado. Compreendendo a matemática presente na obra e, se possível, relacionando com a matemática atual. 
No referido ano, o século sugerido para efetuarem o seminário foi o século XV. Para encontrarem os(as) cientistas que viveram nesse período, foi indicado o site Mac Tutor ${ }^{1}$, principalmente a aba "Chronology Index" que, em uma busca primária, resultou em 13 cientistas que contribuíram para a Matemática ao longo do século sugerido, como exemplificado na figura 1.

Figura 1: Cientistas do século XV

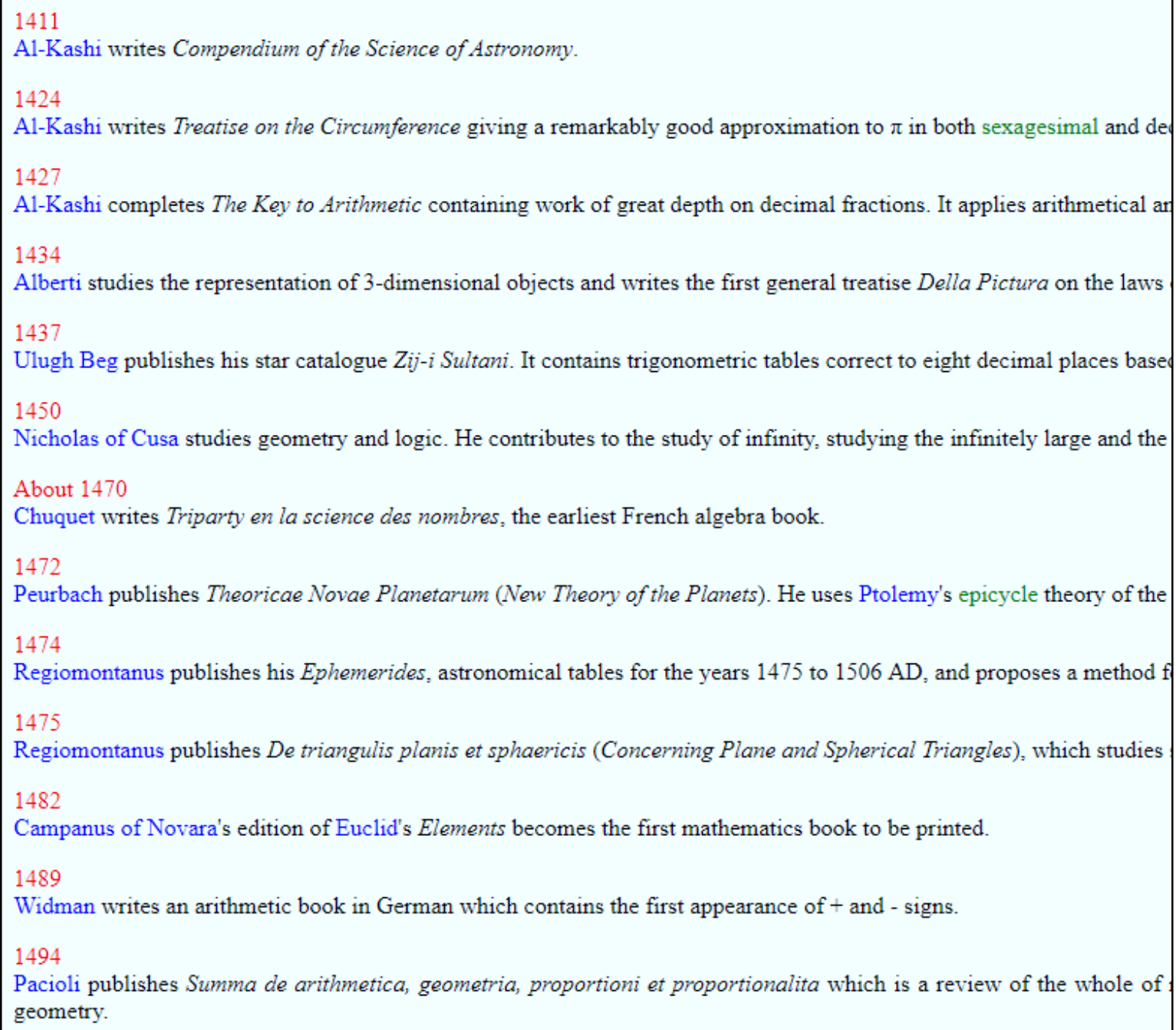

Fonte 1: Mac Tutor. Disponível em: http://wwwhistory.mcs.stand.ac.uk/Chronology/1300_1500.html

Foi explicado aos(às) alunos(as) que no próprio site Mac Tutor, há possibilidade de investigar a biografia e os resultados científicos do autor escolhido. Como por exemplo, poderíamos escolher Regiomontanus, que na lista aparece com dois trabalhos distintos. Ao

${ }^{1}$ http://www-history.mcs.st-and.ac.uk/ 
clicar em um dos nomes, abrirá outra janela, que remeterá a biografia completa. Como na figura 2 .

Figura 2: Biografia Completa de Regiomontano

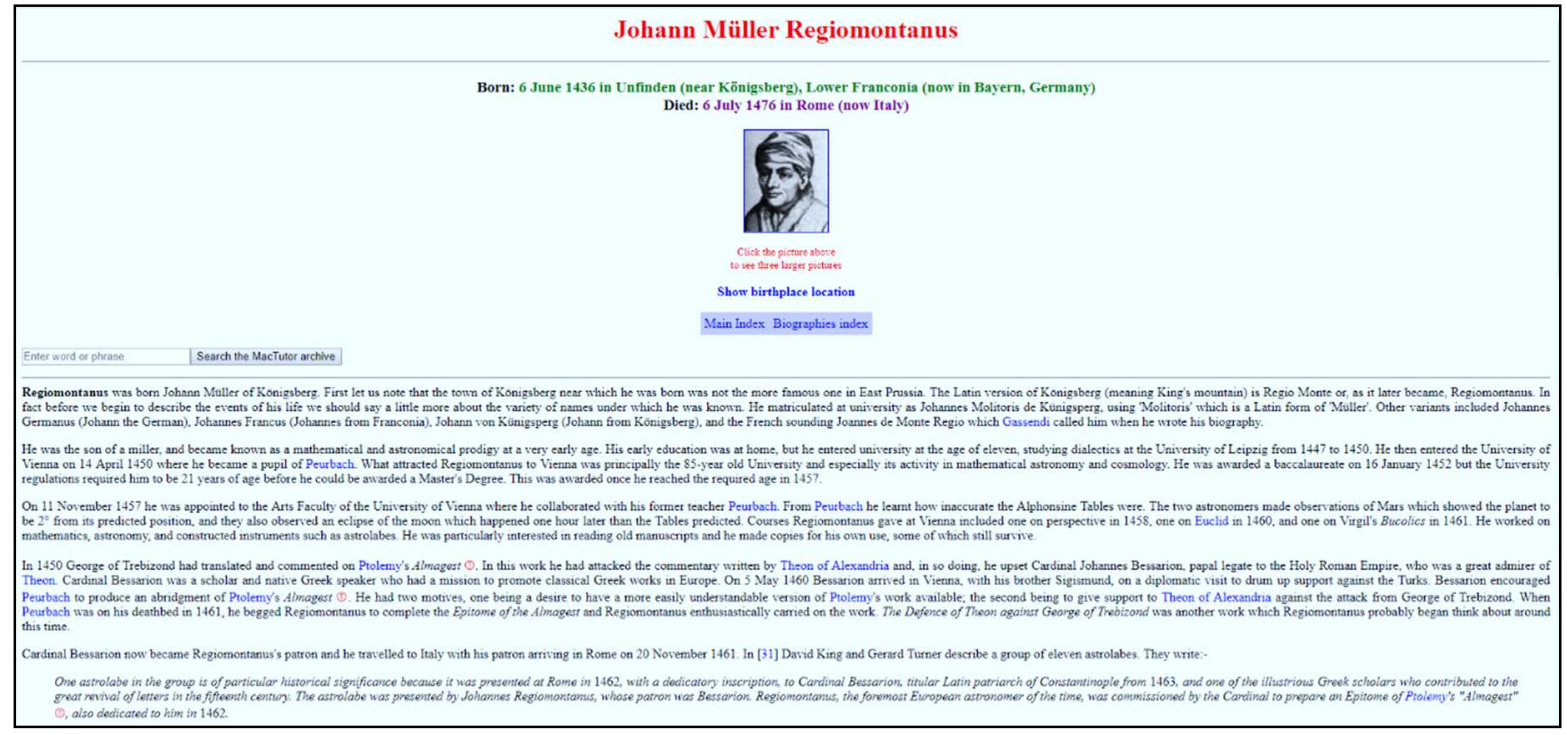

Fonte 2: http://www-history.mcs.st-and.ac.uk/Biographies/Regiomontanus.html

Esse seminário deve ser apresentado em sala de aula e deve ser entregue um trabalho escrito. O principal é que o(a) aluno(a) deve mostrar o conteúdo matemático usando a matemática da época. Ele pode até usar a matemática atual para compreender o que o cientista escolhido estava fazendo, mas para apresentar ele deve usar a matemática que o cientista usou, além de contextualizar a situação dada: qual o problema a ser resolvido? Como foi resolvido? É válido para qualquer tipo de problema dessa natureza? São algumas das perguntas que o(a) aluno(a) deve responder.

\section{Alguns Resultados}

Até o ano de 2019 foram apresentados cerca de 40 trabalhos e seminários. Na tabela 1 pode ser verificado o ano da Educação Básica (Ensino Fundamental (EF) ou Ensino Médio (EM)) para a realização do Trabalho e o século especificado para cada semestre letivo na realização do Seminário.

Tabela 1: Especificação de anos e séculos 


\begin{tabular}{ccc}
\hline Ano & Trabalho & Seminário \\
\hline $\mathbf{2 0 1 2} 2$ & livre & - \\
\hline $\mathbf{2 0 1 3} 1$ & livre & - \\
\hline $\mathbf{2 0 1 3 2}$ & livre & Século XV \\
\hline $\mathbf{2 0 1 4} 1$ & livre & Século XV \\
\hline $\mathbf{2 0 1 4 2}$ & livre & Século XVI \\
\hline $\mathbf{2 0 1 5} 1$ & $9^{\circ}$ ano do EF & Século X \\
\hline $\mathbf{2 0 1 5 2}$ & $9^{\circ}$ ano do EF & Século X \\
\hline $\mathbf{2 0 1 6 ~ 1}$ & $3^{\circ}$ ano do EM & Século XIII \\
\hline $\mathbf{2 0 1 6 2}$ & $6^{\circ}$ ano do EF & Século XVIII \\
\hline $\mathbf{2 0 1 7 ~ 1}$ & $9^{\circ}$ ano do EF & Século V \\
\hline $\mathbf{2 0 1 7 2}$ & $7^{\circ}$ ano do EF & Século XVII \\
\hline $\mathbf{2 0 1 8 ~ 1}$ & $9^{\circ}$ ano do EF & Século X \\
\hline $\mathbf{2 0 1 8 ~ 2}$ & $1^{\circ}$ ano do EM & Século XI \\
\hline $\mathbf{2 0 1 9} 1$ & $3^{\circ}$ ano do EM & Século XII \\
\hline $\mathbf{2 0 1 9 2}$ & $8^{\circ}$ ano do EF & Século VI \\
\hline
\end{tabular}

Fonte 3: Planos de ensino $2012-2019$

Dos seminários realizados desde 2012 a 2019 na UFTM, os(as) alunos(as) relataram algumas dificuldades, entre elas, a mais pertinente é falta de bibliografia em português.

Os livros sobre História da Matemática disponíveis na biblioteca da universidade, são de coleções não atuais. E autores de livros de História da Matemática do século XX contrastam com as ideias dos(as) autores(as) deste tipo de livro do século XXI.

Quando esse fato ocorre, os(as) alunos(as) buscam as fontes originais e, esperam encontrar textos escritos em inglês, por julgarem de fácil tradução. Nem sempre o conseguem. Em muitos dos trabalhos apresentados, os(as) alunos(as) se esforçam por utilizarem as fontes primárias que encontram nos sites, levando em consideração o que foi discutido em sala de aula sobre as interpretações dos historiadores. Relatam as dificuldades e as enfrentam.

As dificuldades aparecem principalmente para realizarem o Seminário, uma vez que precisam saber como o(a) cientista efetuou os cálculos, usando a matemática da época em que viveram. Na figura 3 é possível verificar um dos relatos dos(as) alunos(as) a esse respeito. 


\section{Conclusões Finais}

Podemos perceber durante a pesquisa para o desenvolvimento do trabalho o quanto foi trabalhoso e difícil encontrar as fontes originais do teorema do matemático Al-Biruni, por ser tratar do século XI. Além de que, as fontes originais são muitas vezes modificadas e traduzidas de diferentes formas.

Para a escolha desse matemático fizemos uma busca sobre outros matemáticos do século XI entretanto não obtivemos sucesso na pesquisa e encontramos o matemático Al-Biruni o qual conseguimos coletar mais informações sobre sua vida e suas contribuições para a ciência.

Figura 3: Depoimento presente no trabalho escrito sobre o Seminário solicitado em 20182 Fonte 4: Trabalho escrito por Silva e Faquim, 20182

Outro relato sobre as dificuldades encontradas:

Figura 4: Depoimento presente no trabalho escrito sobre o Seminário solicitado em 20181

No processo de desenvolvimento do trabalho encontramos algumas dificuldades, devido a falta de informação sobre a vida do matemático Abu Kamil, principalmente para encontrar trabalhos realizados por ele. Após encontrar um resultado desenvolvido por ele, tivemos a dificuldade de entender o método matemático utilizado, pelo fato do artigo encontrado ser em outro idioma, e houve a dificuldade em relação a linguagem matemática utilizada pelo autor na época.

Esse trabalho nos proporcionou uma visão de como era tratada a matemática no século $X$, especificamente no mundo árabe, nos mostrando a importância desses matemáticos no desenvolvimento da matemática, nos mostrando que esse desenvolvimento não aconteceu somente na Europa.

Fonte 4: Trabalho escrito por Dias e Cândido, 20181

Ainda sobre os seminários, apesar das dificuldades enumeradas, os(as) alunos(as) fazem um excelente trabalho. Apresentam o(a) cientista escolhido, respeitando a época solicitada, contextualizam esse(a) cientista, apresentam o problema e a sua solução, mesmo quando o documento encontrado precisa de tradução. A qualidade tem sido tão boa que os(as) alunos(as) são convidados a publicar seus trabalhos na semana acadêmica da matemática da 
UFTM (SEMAT - UFTM), como podem ser vistos nos anais do evento e representado aqui como figura 5. No evento ocorrido em 2018 foram aceitos cinco trabalhos na área de História da Matemática para apresentação oral, destes, três são decorrentes da disciplina, os outros dois são de alunos de iniciação científica.

Figura 5: Sumário dos Anais da IX SEMAT UFTM

\section{COMUNICAÇÕES ORAIS}

- A MEDIDA DO "RAIO" E DA "CIRCUNFERENCIA" TERRESTRE POR AL-BIRUNI- $-\mathbf{0}-\mathbf{0 7 - 1 5}$

- a CATENÁRIA: UMA ABORDAGEM HISTÓRICA _ _ 16-23

- uM olhar sobre a PROP. XXXII DE JAMES GREGORY

- FILOSOFO do SÉCULO XI - OMAR KHAYYAM -

- anÁlise dos trabalhos do encontro nacional de educação matemática (ENEM), ENTRE 2010 E 2016, REFERENTE AO USO DE TECNOLOGIAS COMO RECURSO PARA A PRÁTICA DOCENTE, NA FORMAÇÄO INICIAL DE PROFESSORES DE MATEMÁTICA -

- EXPERIÊNCIAS MATEMÁTICAS DE ALUNOS JOVENS E ADULTOS: um estudo nos GT18 e GT19 da ANPEd

- MATEMÁtICA CHINESA do SÉCULO XI: UM BREVE RECORTE SOBRE JIA XIAN E O MÉTODO ADITIVO-MULIPLICATIVO PARA EXTRAÇOES DE RAIZ _.

- PRODUTOS NOTÁVEIS E QUADRILÁTEROS: UMA EXPERIENNCIA A PARTIR DO $\mathrm{PIBIB} / U F T M$ -

- AL-BIRUNI E A DEMONSTRAÇÃo DE UM DE SEUS TEOREMAS

- A IMPORTÂNCIA DOS JOGOS MATEMÁtICOS NO ENSINO DE PROBABILIDADE NO ENSINO FUNDAMENTAL -

- RELAÇÃo ENTRE IMAGEM E ESCRITA PARA AS CIÊNCIAS EXATAS.

- O PIBID E OS PROFESSORES SUPERVISORES DE MATEMÁTICA NOS TRABALHOS PUBLICADOS NA ANPED DE 2010 A 2017 -

ANAIS da VII Semana da Matemática da UFTM - Evento realizado de 17 a 21/10/2016

Fonte 2: Anais da IX SEMAT - UFTM

Em relação aos trabalhos sobre História da Matemática em sala de aula, alguns deles não são originais, os(as) alunos(as) procuram trabalhos prontos e os reinterpretam de modo excelente. Outros aproveitam a oportunidade e demonstram a criatividade. Como exemplo, 
posso citar a turma do segundo semestre de 2019 (2019 2). Foram apresentados cinco trabalhos, uma vez que foi compactuado realizar essa atividade em grupo. Destes, dois apresentaram o conteúdo usando a História da Matemática aliando com a tendência Jogos. Um deles desenvolveu a atividade em sala de aula propondo dois grandes grupos: Babilônios e Egípcios. O grupo dos Babilônios só poderia resolver os problemas apresentados usando as técnicas dessa civilização e o grupo dos Egípcios só poderia resolver os problemas usando as técnicas egípcias. Ganharia pontos o grupo que resolvesse o problema usando a técnica adequada.

$\mathrm{Na}$ sala de aula da UFTM os(as) alunos(as) já haviam aprendido sobre essas civilizações, o autor do trabalho, Pimenta (2019), disse que "na sala de aula da educação básica essas técnicas deveriam ser ensinadas antes de ir para o jogo". Os demais alunos o questionaram, uma vez que agindo dessa maneira, não estaria usando a História da Matemática para ensinar o conteúdo. O autor refletiu e se propôs a usar a História da Matemática para ensinar sobre as civilizações e suas contribuições à Matemática e, depois, aplicaria o jogo. Um problema apresentado foi o seguinte: Qual o resultado da soma de 1.133 com 455? Outro problema foi: Qual a área de um trapézio reto de altura $2 \mathrm{~cm}$, base menor $4 \mathrm{~cm}$, base maior $5 \mathrm{~cm}$ ? Ao final, o(a) aluno(a) que apresentou este trabalho resolveu as questões usando as técnicas de ambos os povos.

Para que os trabalhos usando a História da Matemática pudessem ser de melhor qualidade uma disciplina específica para abordar essa tendência seria necessária. Como uma sugestão dada a mim pelos(as) alunos(as) da disciplina. Ainda assim, se dizem à vontade para preparar uma aula usando essa tendência metodológica.

Pensando nas aulas presenciais, nas avaliações individuais dadas, após dez anos de prática em sala de aula do ensino superior e, visando atingir os objetivos da disciplina, percebi que minha postura deve ser diferente nos próximos semestres, uma vez que o diálogo não vem acontecendo como gostaria.

A aula dialogada proposta no plano de ensino deveria ocorrer sempre, mas os(as) alunos(as) estão acostumados em "receber" a informação e não se movimentam a procura dela, o que se torna contraditório em nossa sociedade, já que temos acesso aos avanços da tecnologia, e nossos(as) alunos(as) a usam constantemente nos processos das práticas sociais, 
precisamos apenas os educar para usarem essa tecnologia a fim de adquirir conhecimento o que corrobora com Cerqueira (2006).

A concepção de sociedade discutida aqui é, portanto, a sociedade que pressupõe a igualdade de oportunidades, de chances entre todos os indivíduos, na qual a educação exerce a importante tarefa de propiciar os instrumentos capazes de colocar os indivíduos em situação de competição pelos privilégios que a sociedade democrática permite alcançar. Imaginamos que praticar essa democracia no espaço escolar é contribuir para a formação de crianças, jovens e adultos para a ética e a cidadania dando-lhes oportunidades de se sentirem proprietários do trabalho que executam. Assim, acreditamos nas possibilidades de termos escolas que desde cedo preparam os seus cidadãos para ter voz ativa, sendo dono de opiniões, pontos de vista; que participem de debates, discussões; que possam cumprir seus deveres e lutarem por seus direitos com autonomia; que possam conquistar sua liberdade de ir e vir agindo na participação das práticas sociais existentes, com dignidade. (CERQUEIRA, 2006, p.31)

Dessa forma, para que o diálogo entre quem aprende e quem ensina esteja mais presente nas aulas, decidi propor a metodologia da sala de aula invertida, isso a partir de 2019 2. Na aula dialogada é que poderei observar como o(a) aluno(a), futuro(a) professor(a), expõe suas ideias, defende seus argumentos, participa de sua formação e de seu colega. Acredito que através dessa metodologia, onde é proposto aos(às) alunos(as) que estudem em casa sobre um tema escolhido e, já definido no cronograma de aulas disponibilizado pela instituição, em que são orientados a usarem todas as ferramentas possíveis: os livros indicados na bibliografia, livros adquiridos em pdf, nos sites sobre História e/ou História da Matemática e nos slides de aulas sobre os temas que são disponibilizados a todos(as), a aula seja melhor aproveitada a fim de que na aula combinada, possamos conversar sobre o assunto pré-definido, realizarmos atividades de resolução de exercícios e compartilhar as dúvidas, tanto minhas quanto a deles. Nesse sentido, me colocarei como mediadora do conhecimento e proponente de atividades que possam causar, provocar a busca pelo conhecimento.

Como essa metodologia foi colocada em prática somente no último semestre ainda não tenho dados suficientes para analisar, a reflexão constante sobre as aulas poderá me direcionar ao caminho mais adequado perante a turma com a qual trabalho. 


\section{Considerações Finais}

Ao longo dos anos tenho refletido sobre as atividades propostas nas aulas da disciplina História da Matemática da UFTM e tenho aprendido muito com os(as) discentes que elaboram as atividades, vejo o protagonismo deles(as), principalmente para realizar os seminários sobre os(as) cientistas e, na realização das atividades dos trabalhos para desenvolver algum conteúdo em sala de aula. Nesse sentido, venho propondo novas formas de abordagem da disciplina, como a metodologia da sala de aula invertida, que foi proposta em 20192 e em 2020 1, como uma resposta à essa postura dos(as) discentes.

A disciplina História da Matemática é ampla e devemos trabalhar com a compreensão da História da Matemática, da História da Matemática no ensino e do campo de pesquisa da História da Matemática e, temos pouco tempo para conversarmos sobre cada um dos campos.

Para resolver esse problema, os(as) alunos(as) indicam que o curso poderia ofertar a disciplina de História da Matemática em três momentos: uma no segundo período do curso, com uma parte de introdução à História da Matemática, trabalhando a História desde os tempos remotos até os Gregos, passando pelos Babilônios e Egípcios, uma no último período do curso, como no modelo que está em vigor, abarcando o período após os Gregos até a atualidade e, uma terceira que poderia ser ofertada não como obrigatória, mas como eletiva ao curso, com abordagem em ensino dos conteúdos matemáticos na educação básica usando a História da Matemática. Esses comentários normalmente aparecem no último dia de aula da disciplina, onde solicito que os(as) alunos(as) a avaliem ao longo do semestre e solicito que indiquem melhorias. Nesses diálogos aparecem os argumentos de que essas mudanças não são fáceis de serem realizadas e mesmo que a fizéssemos vem a pergunta: não iremos precisar de outra(s) disciplina(s)? Uma ou duas ou três disciplinas não irão conseguir satisfazer todos os anseios? Precisamos continuar a estudar e a pesquisar sempre. Somos professores pesquisadores e, para tanto, se torna necessário sermos parceiros(as), um(a) apoiando o(a) outro(a), em qualquer ambiente.

Ser professora me orgulha muito, pensar sobre a forma de lecionar esta disciplina, e as demais, vem sendo refletida e alterada conforme os resultados nas atividades propostas em sala de aula. Esse movimento dinâmico compactua com a História da Matemática e de seu ensino. Não há uma forma "pronta e acabada" para a lecionar. Vamos moldando a aula conforme conhecemos nossos(as) alunos(as). 


\section{Referências}

BARRETO, F. C. de S., OLIVEIRA, C. A. S. de \& BEZERRA, R. C. F. B. (2002) CNE/CES 1.302/2001. Despacho do Ministro em 4/3/2002, publicado no Diário Oficial da União de 5/3/2002, Seção 1, p. 15.

CERQUEIRA, T. C. S. (2006) O professor em sala de aula: Reflexão sobre os estilos de aprendizagem e a escuta sensivel. Psic, 7 (1) 29-38. Vetor Editora.

GASPAR, M. T. de J. (2003) Aspectos do desenvolvimento do Pensamento geométrico em algumas civilizações e povos e a formação de professores. (Dissertação de Doutorado, Universidade Estadual Paulista, Brasil, São Paulo: Rio Claro).

LOPES, L. S. \& FERREIRA, A. L. (2013) A. Um olhar sobre a história nas aulas de matemática. Abakós, 2 (1) 75 - 88. Brasil, Minas Gerais: Belo Horizonte.

MENDES, I. A. (2008) Tendências metodológicas no ensino de matemática. Brasil, Pará, Belém: EdUFPA.

NOBRE, S. (2004) Leitura crítica da história: Reflexões sobre a história da matemática. Ciência e educação, 10 (3), 531-543.

NOBRE, S. (2012) A disciplina acadêmica "História da Matemática" na formação de profissionais em matemática. Educ. Matem. Pesq., 14 (3), 507-524.

O'Connor, J.J. \& Robertson, E.F. (2015). Chronology for 1300 to 1500. Mac Tutor. Disponível em: http://www-history.mcs.st-and.ac.uk/Chronology/1300 1500.html Acesso em 10 de mar de 2019.

SILVA, G. R. B. \& FAQUIM, L.C.B. (2018) Al-Biruni e a demonstração de um de seus teoremas. Anais IX SEMAT, 73-79. Brasil, Minas Gerais: Uberaba. Disponível em https://sistemas.uftm.edu.br/integrado/?to=N29zTFVkdGh2bjcyeC9odGFISIRIRGthNjZ1VW Y5Z1N1blFtdTJLUnFmbDdkU0V1YzVvZEtjbkZhTyt2UFBaeXRFSnpFbEMweitJNWV6NX R3RWZBVGE2T2dYMityc3JqbVp5UitkT3Z4LzFiNFNtNHdwU2ZNRTQ0R3RCVURjenlu R0hnVzE4Ynd2T0psYkdwZFJUeHRpTXBUQmVDVFNyM1FZZFM1Mzd4VHpENFIBTHp 0MTlFRmdndkdMVU15VDNx\&secret=uftm

SIQUEIRA MARTINES, M. C. (2012-2019) Plano de Ensino da disciplina História da Matemática. UFTM. Disponível em https://siscad.uftm.edu.br/titan.php?toSection=1\&toAction=view\&itemId=45276\&page=1\&pe $\underline{\mathrm{sq} 0}=\&$ pesq $1=\&$ disciplinaCodigo $=25030000667$

Autora

Mônica de Cássia Siqueira Martines

Doutorado em Educação Matemática pela Universidade Estadual Paulista Júlio de Mesquita Filho (UNESP/Rio Claro, 2014). Mestrado em Educação Matemática pela Universidade 
Estadual Paulista Júlio de Mesquita Filho (UNESP/Rio Claro, 2009). Licenciatura em Matemática (1999). Atualmente é professora adjunta da Universidade Federal do Triângulo Mineiro (UFTM). Tem experiência na área de História da Matemática. Mais informações no Currículo Lattes: http://lattes.cnpq.br/6625047361725116. ORCID: https://orcid.org/00000002-3143-9206.E-mail: monicasiqueiramartines@gmail.com 